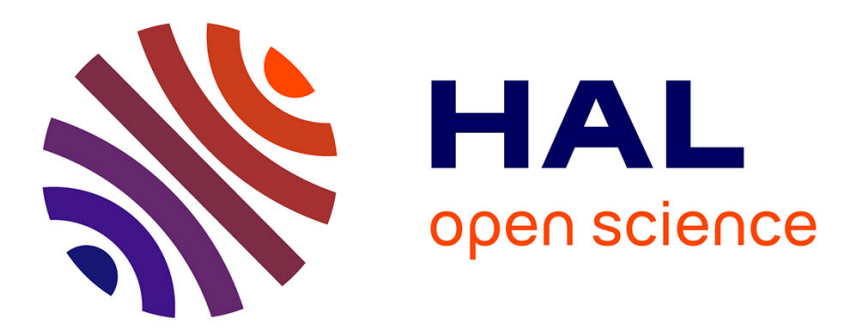

\title{
Designing the high voltage transformer of power supplies for DBD: Windings arrangment to reduce the parasitic capacitive effects
}

Xavier Bonnin, Hubert Piquet, Rafael Diez, David Florez

\section{To cite this version:}

Xavier Bonnin, Hubert Piquet, Rafael Diez, David Florez. Designing the high voltage transformer of power supplies for DBD: Windings arrangment to reduce the parasitic capacitive effects. Power Electronics and Applications (EPE), 2013 15th European Conference on, Sep 2013, Lille, France. pp. 1-9, 10.1109/EPE.2013.6631928 . hal-01444212

\author{
HAL Id: hal-01444212 \\ https://hal.science/hal-01444212
}

Submitted on 23 Jan 2017

HAL is a multi-disciplinary open access archive for the deposit and dissemination of scientific research documents, whether they are published or not. The documents may come from teaching and research institutions in France or abroad, or from public or private research centers.
L'archive ouverte pluridisciplinaire HAL, est destinée au dépôt et à la diffusion de documents scientifiques de niveau recherche, publiés ou non, émanant des établissements d'enseignement et de recherche français ou étrangers, des laboratoires publics ou privés. 


\section{Open Archive Toulouse Archive Ouverte (OATAO)}

OATAO is an open access repository that collects the work of Toulouse researchers and makes it freely available over the web where possible.

This is an author-deposited version published in: http://oatao.univ-toulouse.fr/ Eprints ID: 17428

To link to this article: DOI: 10.1109/EPE.2013.6631928

URL : https://doi.org/10.1109/EPE.2013.6631928

To cite this version: Bonnin, Xavier and Piquet, Hubert and Diez, Rafael and Florez, David Designing the high voltage transformer of power supplies for DBD: Windings arrangment to reduce the parasitic capacitive effects. (2013) In: Power Electronics and Applications (EPE), 2013 15th European Conference on, 2 September 2013 - 6 September 2013 (Lille, France)

Any correspondence concerning this service should be sent to the repository administrator: staff-oatao@listes-diff.inp-toulouse.fr 


\title{
Designing the high voltage transformer of power supplies for DBD: windings arrangment to reduce the parasitic capacitive effects
}

\author{
Xavier BONNIN ${ }^{1}$, Hubert PIQUET ${ }^{1}$, Rafael DIEZ ${ }^{2}$, David FLOREZ ${ }^{1,2}$ \\ ${ }^{1}$ Laboratoire LAPLACE \\ ${ }^{2}$ Pontificia Universidad Javeriana \\ UMR 5213 CNRS INP UPS Department of Electronics \\ 2, rue Charles Camichel, Carrera 7 No. 40 - 62 \\ 31071 Toulouse, FRANCE Bogotà D.C., COLOMBIA
}

Email: xavier.bonnin@laplace.univ-tlse.fr

\section{Acknowledgments}

The authors are grateful to the French-Colombian cooperation (ECOS Nord, COLCIENCIAS-ICETEX program) and to the French Midi-Pyrénées region for support.

\section{Keywords}

$<<$ winding arrangement $>>,<<$ parasitic capacitance $>>,<<$ dielectric barrier discharge $>>,<<$ high voltage transformer $>>$,

\begin{abstract}
In Dielectric Barrier Discharges (DBDs), the control of the power transfer, from the low-voltage static converter to the high voltage DBD, is strongly affected by the parasitic capacitive effects of the step-up transformer. Minimizing these capacitances is of major importance and this paper aims to establish and validate analytical expressions in order to predict the values of the parasitic capacitances of high ratio, step-up transformers, according to different windings arrangements using cylindrical conductors. Afterward, experimental validations are performed on three transformers which have been realized according to same specifications, in order to show the accuracy of the method and to understand the influence the winding arrangements on the capacitive parasitic effects.
\end{abstract}

\section{Introduction}

Dielectric Barrier Discharges (DBD) are widely used nowadays in numerous applications [1] where plasma is required to have large surface pattern and low temperature: surface treatments [2], microlithography, ozone generation [3], UV generation [4], lighting and displays, among others. Fig.1 reminds the principle of topologies, proposed on the basis of causality reasoning [5, 6], to supply DBD devices with an efficient control of the operating conditions. It exhibits an equivalent circuit of the DBD, which is modeled as follows [7]: $C_{d}$ represents the dielectric barriers that separate the discharge gas from the power supply metallic electrodes; $C_{g}$ characterizes the gas when it is non-conducting and $G_{\text {gas }}$ stands for the gas conductance after its breakdown. The typical almost constant voltage across the gas after breakdown $\left(+V_{t h}\right.$ or $\left.-V_{t h}\right)$ [8], along with the capacitive nature of the DBD, implies a bidirectional current-mode converter, in order to satisfactorily supply the DBD. The typical operating conditions of a 


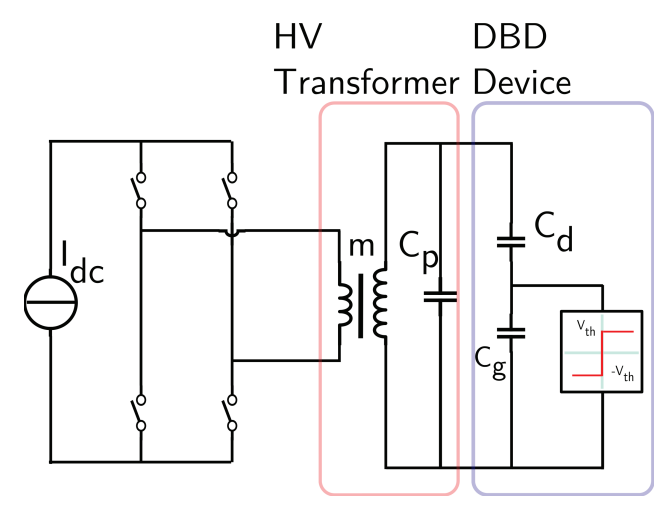

Fig. 1: Current controlled source to supply DBD devices

$\mathrm{DBD}$, with up to several $\mathrm{kV}$ voltage, leads to the use of a step-up transformer, interconnecting the lowvoltage converter with the DBD. Frequently, the capacitance values for the DBD, $C_{d}$ and $C_{g}$, are very low (tenths of $\mathrm{pF}$ )[7] : due to this fact, the construction of the transformer becomes a challenge, since the current injected in the primary side divides between the parasitic capacitances of the transformer (here simply and globally represented as $C_{p}$ ) and the equivalent DBD capacitance [9]. As a matter of fact, the parasitic capacitances of the transformer strongly decrease the power injected in the DBD; this issue highlights the crucial importance of the transformer design. Considering the need of reducing the parasitic capacitances of the step-up transformer, this paper proposes a simple method to predict the values of the parasitic capacitances in a high voltage, highly coupled, two-winding transformer: starting from the geometry of the transformer, analytical equations are established. Afterward, the results of this method are experimentally validated and different winding configurations are compared.

\section{Two windings high-voltage transformer electrical model}

\section{Lumped parameters equivalent circuits}

A general methodology suitable for the study of lossless multi-winding transformers is detailed in [10]. An equivalent circuit for a two-winding transformer is remembered in Fig.2a. In the present work we limit to an electrostatic study, and assume that the resonances with the leakage inductance of the transformer occur at frequencies higher than the converter switching frequency. The meaning of this assumption is that the transformer windings exhibit a high coupling factor. Consequently, we take the secondary voltage $V_{2}$ proportional to the primary voltage $V_{1}$, giving $V_{2}=m V_{1}$, being $m$ the transformation ratio and consider the ideal transformer which appear in Fig.2b. Under this assumption, the model is reduced to two independent voltages $\left[V_{1} V_{3}\right]$ instead of 3 . Thus, the electrostatic behavior can be accounted with 3 independent capacitances as shown in Fig.2b. Summing the stored energy in each capacitance, the electrostatic energy is given by the following quadratic form:

$$
\begin{aligned}
W & =\frac{1}{2} C_{1} V_{1}^{2}+\frac{1}{2} C_{2}\left(V_{3}-m V_{1}\right)^{2}+\frac{1}{2} C_{3}\left(V_{3}+(1-m) V_{1}\right)^{2} \\
& =\frac{1}{2}\left[\left(C_{1}+m^{2} C_{2}+(m-1)^{2} C_{3}\right) V_{1}^{2}+\left(C_{2}+C_{3}\right) V_{3}^{2}-2\left(m C_{2}+(m-1) C_{3}\right) V_{1} V_{3}\right]
\end{aligned}
$$

\section{Estimation of the capacitance values}

Different transformer winding arrangements, as shown in Fig.4 and illustrated on Fig.3, are studied in this paper. We assume a double $\mathrm{E}$ shaped magnetic core and the winding realization is basically defined by two integer numbers, $N_{s}$ and $N_{l}$. The secondary winding may be splitted in $N_{s}$ sections. Transformers of Fig.4a and Fig.4b are not splitted: $N_{s}=1$ although Fig.4c and Fig. 3 exhibit two sections: $N_{s}=2$. Insulating flanks of the coilformer are separating the consecutive sections. In each section, the turns are 


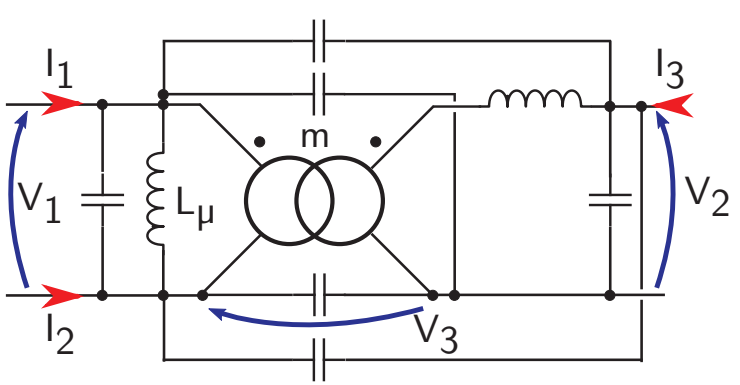

(a)

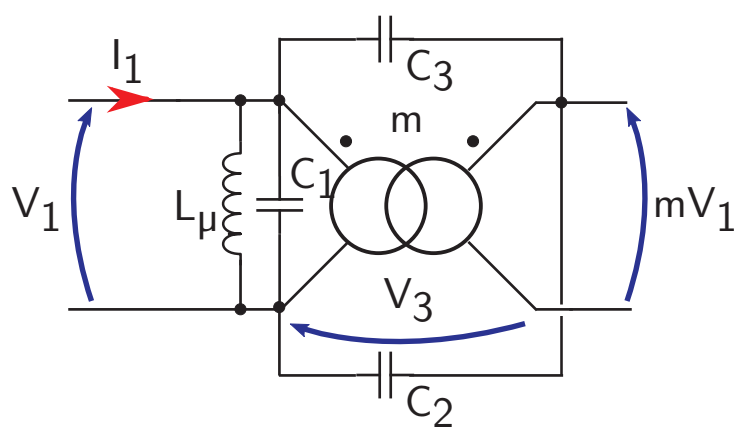

(b)

Fig. 2: Lossless transformer model. General model (a) and low frequency model (b).
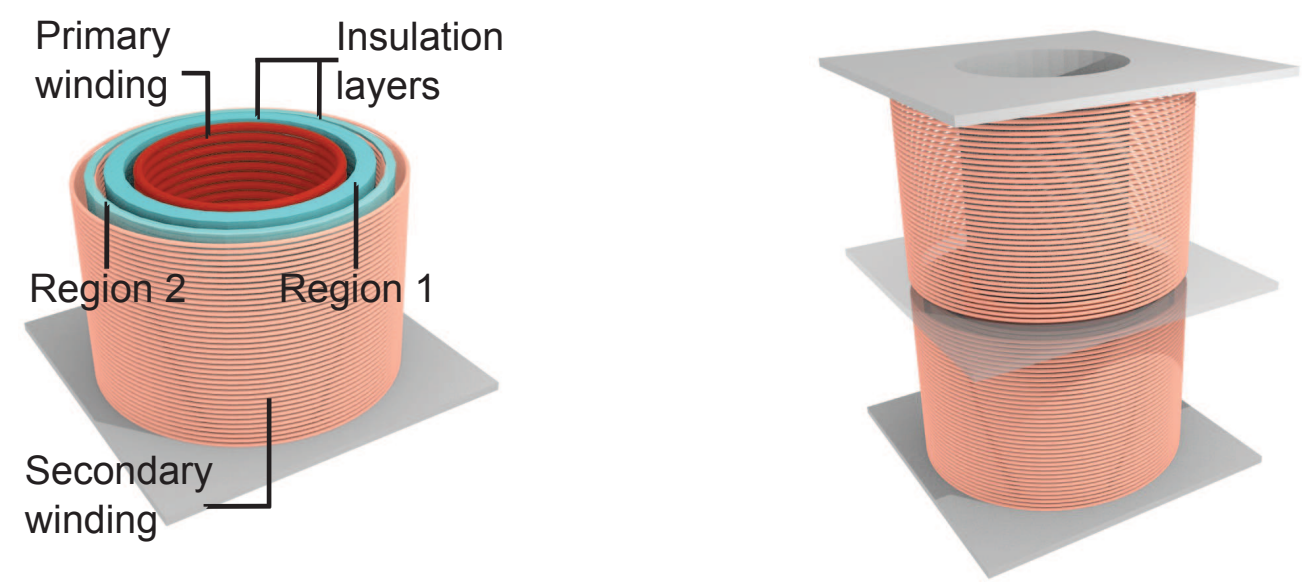

Fig. 3: Construction of a two sections / two layers $\left(N_{s}=2 / N_{l}=2\right)$ transformer. Magnetic core not presented.

arranged in $N_{l}$ layers separated with insulating layers of $E_{l l}$ thickness. To note that at the end of a layer (say layer $k$ ), the next turn, which belong to the layer $k+1$, has to be wound just over the first turn of the layer $k$. This method leads to the voltage distribution sketched on Fig.5b. A free air space with $E_{2 c}$ thickness is kept between the external secondary layers and the outer legs of the magnetic core. A free space (air) with $E_{2 c}$ thickness is kept between the external secondary layers and the outer legs of the magnetic core.

\section{Simple electrostatic studies}

With the aim of finding the parasitic capacitances in each configuration, we remind here the results of two simple electrostatic problems; those are needed to understand the electrostatic effects in our lossless highly coupled high ratio transformer. The results will be used to calculate the electrostatic energy stored in the regions of type 1,2 and 3; implying that the energy stored apart from these regions - say the region between two adjacent sections, the region around the transformer- is neglected. This approximation is supposed relevant since the considered structures are such as most of the electrostatic energy is located in these regions. For our interest, two cases of distribution of potential are studied:

- the first one Fig.5a serves at modeling the cases of region 1 and region 3 (see Fig.3 and 4d) since one of the layer is assumed to be equipotential although the second one is assumed to be charged such as its potential is linearly growing,

- the second one Fig.5b serves at modeling the case of region 2 since the potential in the two layers is linearly growing. 


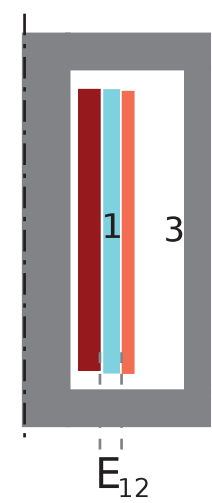

(a)

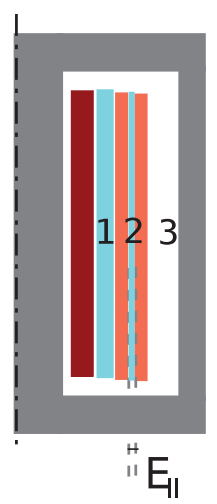

(b)

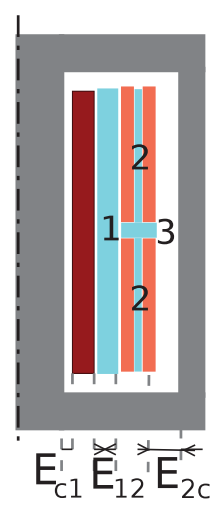

(c)

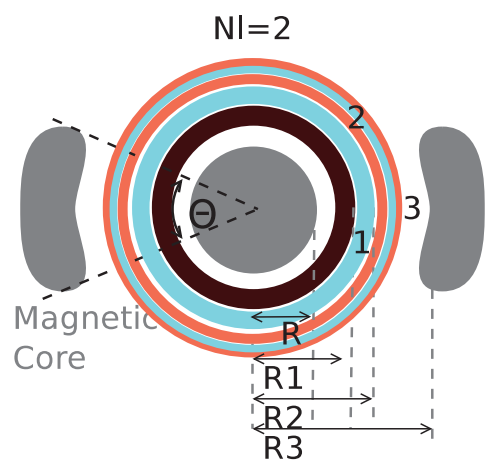

(d)

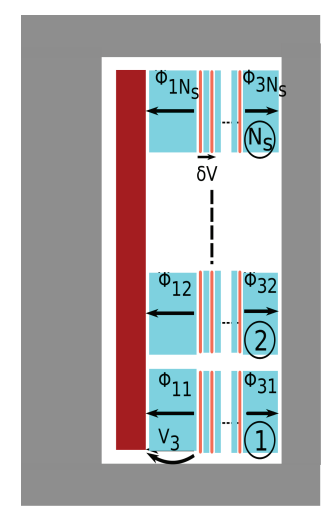

(e)

Fig. 4: Internal structure of the three transformers under study. $N_{l}=1$ in (a), $N_{l}=2$ in (b) and (c) ; $N_{s}=1$ in (a)(b) and $N_{s}=2$ in (c). $N_{l}$ and $N_{s}$ are respectively the numbers of layers and sections in the secondary winding. General case (e).

Linearly charged plate versus grounded conducting plate: the situation is illustrated in Fig.5a. It is to note that the configuration is invariant by translation along $(O, y)$. The charge density is assumed to be such as the potential is growing linearly from $-V_{3}$ (bottom edge of the plate) to $-V_{3}+m V_{1}$ (top edge). $\phi=-m V_{1} / 2+V_{3}$ is the potential difference between the primary winding (assumed to be equipotential due to the high transformation ratio value) and the middle point of the secondary winding. The electric potential can be found by searching a potential solution of the form $V(x, z)=E_{0} x+E_{1} z+A x z$, where $x$ and $z$ are the space variables for the two-dimensions problem. It is noted that such a function satisfies Laplace equation $\Delta V=0$. Moreover, writing the boundary conditions leads to

$$
\left\{\begin{array}{l}
V(0, z)=0 \\
V(e, z)=-\left(\phi+0.5 m V_{1}\right)+\frac{z}{H} m V_{1},
\end{array}\right.
$$

giving

$$
\left\{\begin{array}{l}
E_{1}=0 \\
E_{0}=-\frac{\left(\phi+0.5 m V_{1}\right)}{e} \\
A=\frac{m V_{1}}{e H} .
\end{array}\right.
$$

Then, the electric field $\vec{E}$ can be calculated by $\vec{E}=-\vec{\nabla} V$. Thus, integrating $\|\vec{E}\|^{2}$ over the volume delimited by the box of dimensions $e \times H \times l$ (Fig.5) allows to express $W$, the stored energy, as:

$$
W=\frac{\varepsilon}{2} \iiint\|\vec{E}\|^{2} d V=\frac{1}{2}\left[\frac{C_{0}}{12}\left(1+4\left(\frac{e}{H}\right)^{2}\right)\left(m V_{1}\right)^{2}+C_{0} \phi^{2}\right],
$$

where $C_{0}=\varepsilon H l / e$ is the capacitance of the system for two perfect conductor plates $\left(m V_{1}=0\right)$, and $l$ is the depth considered to calculate the electrostatic stored energy as it is shown in Fig.5a.

Two linearly charged plates: This situation, presented in Fig.5b, is used to model the capacitive effects between two adjacent layers of the secondary winding. The two parallel layers are charged such as the potential is growing linearly of an amount $\delta V$ from the bottom edge to the top edge. Solving Laplace equation with the same method used previously and integrating the squared norm of the electric field over the volume gives the stored energy as:

$$
W=\frac{1}{2}\left[1+\left(\frac{e}{H}\right)^{2}\right] C_{0} \delta V^{2} .
$$




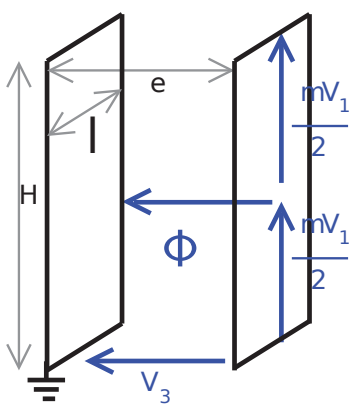

(a)

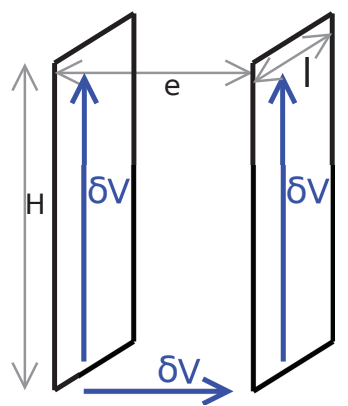

(b)

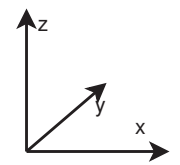

Fig. 5: Two electrostatic problems.

\section{Study of three cases for the secondary winding arrangement}

The various arrangements of the secondary winding presented in Fig.4 are now analyzed. In the following lines, we calculate the electrostatic energy which is stored in the volume of the transformer as a function of $V_{1}$ and $V_{3}$ in order to calculate the values of $C_{1}, C_{2}$ and $C_{3}$ by identifying the quadratic form coefficients of the energy with those of (1).

Case 1: one-section/one-layer, highly coupled, high ratio step-up transformer : in this case presented on Fig.4a, we consider that the main part of the stored energy is in the regions 1 and 3. Actually the regions 1 and 3 are delimited by two concentric cylinder portions which height is called $H$ but we accept the approximation that they are delimited by two parallel planes since the insulation thickness is assumed to be much smaller than the inner cylinder radius. According to the assumption that $V_{1}$ can be neglected compared to $m V_{1}$, the primary winding is assumed to be equipotential. Thus, using (4) by replacing $e$ by $E_{12}$ and $l$ by $\pi\left(R_{1}+R_{2}\right)$ leads to express the electrostatic energy stored in the region 1 :

$$
W_{1}=\frac{1}{2}\left[\frac{\tilde{\gamma}_{1}}{12}\left(1+4\left(\frac{E_{12}}{H}\right)^{2}\right)\left(m V_{1}\right)^{2}+\tilde{\gamma}_{1} \phi^{2}\right],
$$

where $\tilde{\gamma}_{1}=\varepsilon_{1} \pi\left(R_{1}+R_{2}\right) H / E_{12}$ and $\phi$ is defined on Fig.5a. Considering that the core is a conductor, the electrostatic energy stored in the region 3 in the transformer can be calculated according to (4) by replacing respectively $e$ and $l$ by $E_{2 c}$ and $\theta\left(R_{3}-E_{2 c}\right)$. It leads to

$$
W_{3}=\frac{1}{2}\left[\frac{\tilde{\gamma}_{3}}{12}\left(1+4\left(\frac{E_{2 c}}{H}\right)^{2}\right)\left(m V_{1}\right)^{2}+\tilde{\gamma}_{3} \phi^{2}\right],
$$

where $\tilde{\gamma}_{3}=\varepsilon_{3} \theta\left(2 R_{3}-E_{2 c}\right) H / E_{2 c}$. Thus, the total electrostatic energy is given by

$$
\begin{aligned}
W & =W_{1}+W_{3} \\
& =\frac{1}{2}\left[\left(\frac{\tilde{\gamma}_{1}}{12}\left(1+4\left(\frac{E_{12}}{H}\right)^{2}\right)+\frac{\tilde{\gamma}_{3}}{12}\left(1+4\left(\frac{E_{2 c}}{H}\right)^{2}\right)\right)\left(m V_{1}\right)^{2}+\left(\tilde{\gamma}_{1}+\tilde{\gamma}_{3}\right) \phi^{2}\right],
\end{aligned}
$$

where $E_{2 c}$ is the distance between the last layer of the secondary winding and the outer legs of the core (Fig.4), and where $\varepsilon_{i}$ is the dielectric permittivity of the zone $i$. Practically, taking into account that $H \gg 2 E_{12}$ and $H \gg 2 E_{2 c}(8)$ is simplified as (9):

$$
\begin{aligned}
W & \approx \frac{1}{2}\left[\frac{m^{2}}{12}\left(\tilde{\gamma}_{1}+\tilde{\gamma}_{3}\right) V_{1}^{2}+\left(\text { tilde } \gamma_{1}+\tilde{\gamma}_{3}\right) \phi^{2}\right] \\
& \approx \frac{\tilde{\gamma}_{1}+\tilde{\gamma}_{3}}{2}\left[\frac{\left(m V_{1}\right)^{2}}{3}+V_{3}^{2}-m V_{1} V_{3}\right]
\end{aligned}
$$

since $\phi=V_{3}-m V_{1} / 2$. 
The other cases: For each section, the electrostatic energy is calculated using (4) for regions of type 1 (insulation region delimited by the primary winding and the first layer of the secondary winding of the current section) and type 3 (regions delimited by the the last secondary layer of the current section and the outer leg of the magnetic core) and (5) for regions 2 (the inter-layer regions). Using the notations of Fig.4e and summing the contribution of each section, the electrostatic energy stored the regions of type 1 is given by :

$$
\begin{aligned}
W_{1} & =\frac{1}{2} \sum_{n=1}^{N_{s}} \gamma_{1}^{\prime}\left[\frac{1}{12}\left(1+4\left(\frac{E_{12}}{H_{s}}\right)^{2}\right)\left(\frac{m V_{1}}{N_{l} N_{s}}\right)^{2}+\phi_{1 n}^{2}\right] \\
& =\frac{\gamma_{1}^{\prime}}{2}\left[\frac{N_{s}}{12}\left(1+4\left(\frac{E_{12}}{H_{s}}\right)^{2}\right)\left(\frac{m V_{1}}{N_{l} N_{s}}\right)^{2}+\sum_{n=1}^{N_{s}} \phi_{1 n}^{2}\right] \\
& \approx \frac{\gamma_{1}^{\prime}}{2}\left[\frac{N_{s}}{12}\left(\frac{m V_{1}}{N_{l} N_{s}}\right)^{2}+\sum_{n=1}^{N_{s}} \phi_{1 n}^{2}\right] \quad \text { if } \quad 4\left(\frac{E_{12}}{H_{s}}\right)^{2} \ll 1,
\end{aligned}
$$

where $\gamma_{1}^{\prime}=\varepsilon_{1} \pi\left(R_{1}+R_{2}\right) H_{s} / E_{12}, H_{s}$ being a section height. The same reasoning applied in the regions of type 3 leads to

$$
\begin{aligned}
W_{3} & =\frac{1}{2} \sum_{n=1}^{N_{s}} \gamma_{3}^{\prime}\left[\frac{1}{12}\left(1+4\left(\frac{E_{2 c}}{H_{s}}\right)^{2}\right)\left(\frac{m V_{1}}{N_{l} N_{s}}\right)^{2}+\phi_{3 n}^{2}\right] \\
& =\frac{\gamma_{3}^{\prime}}{2}\left[\frac{N_{s}}{12}\left(1+4\left(\frac{E_{2 c}}{H_{s}}\right)^{2}\right)\left(\frac{m V_{1}}{N_{l} N_{s}}\right)^{2}+\sum_{n=1}^{N_{s}} \phi_{3 n}^{2}\right] \\
& \approx \frac{\gamma_{3}^{\prime}}{2}\left[\frac{N_{s}}{12}\left(\frac{m V_{1}}{N_{l} N_{s}}\right)^{2}+\sum_{n=1}^{N_{s}} \phi_{3 n}^{2}\right] \text { if } 4\left(\frac{E_{2 c}}{H_{s}}\right)^{2} \ll 1,
\end{aligned}
$$

where $\gamma_{3}^{\prime}=\varepsilon_{3} \theta\left(2 R_{3}-E_{2 c}\right) H_{s} / E_{2 c}, H_{s}$ being a section height. Summing the electrostatic energies stored in each inter-layer region leads to express the total inter-layer energy by

$$
\begin{aligned}
W_{2} & =N_{s} \sum_{m=1}^{N_{l}} \frac{\gamma_{2_{m}}^{\prime}}{2}\left(1+\left(\frac{E_{l l}}{H_{s}}\right)^{2}\right) \delta V^{2} \\
& =\frac{N_{s} N_{l} \gamma_{2}^{\prime}}{2}\left(1+\left(\frac{E_{l l}}{H_{s}}\right)^{2}\right) \delta V^{2} \\
& \approx \frac{N_{s} N_{l} \gamma_{2}^{\prime}}{2} \delta V^{2} \quad \text { if } \quad\left(\frac{E_{l l}}{H_{s}}\right)^{2} \ll 1,
\end{aligned}
$$

where $\gamma_{2_{m}}^{\prime}=\varepsilon_{2} 2 \pi \bar{R}_{m}^{\text {layer }} H_{s} / E_{l l}, \bar{R}_{m}^{\text {layer }}$ being the radius of the mean cylinder defined by $m^{\text {th }}$ inter-layer region and where $\gamma_{2}^{\prime}=\varepsilon_{2} 2 \pi \bar{R}^{\text {layer }} H_{s} / E_{l l}, \bar{R}^{\text {layer }}$ being the radius of the mean cylinder delimited by the first and the last secondary layer. Then, considering that

$$
\begin{aligned}
\phi_{1 n} & =V_{3}-\frac{m V_{1}}{2 N_{s} N_{l}}-(n-1) \frac{m V_{1}}{N_{s}} \\
\phi_{3 n} & =V_{3}-\frac{\left(2 N_{l}-1\right) m V_{1}}{2 N_{s} N_{l}}-(n-1) \frac{m V_{1}}{N_{s}} \text { and } \\
\delta V & =\frac{m V_{1}}{N_{s} N_{l}}
\end{aligned}
$$

and summing (10), (11), (12) leads to

$$
W=W_{1}+W_{2}+W_{3}=\frac{1}{2}\left\{\left[a \gamma_{1}+b \gamma_{2}+c \gamma_{3}\right] V_{1}^{2}+d\left[\gamma_{1}+\gamma_{3}\right] V_{3}^{2}+\left[e \gamma_{1}+f \gamma_{3}\right] V_{1} V_{3}\right\}
$$




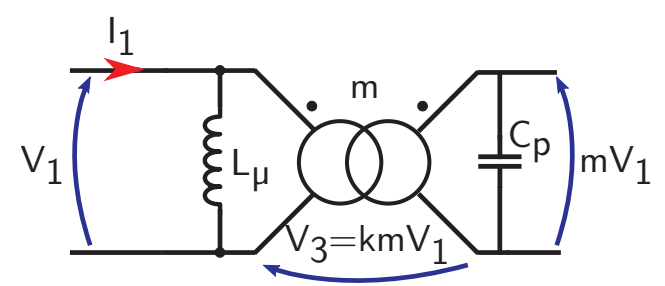

Fig. 6: Low frequency electrical model of a two winding transformer when $V_{3}$ is known as a function of $V_{1}$.

where the parameters $a, b, c, d, e$ and $f$ are given by

$$
\left\{\begin{array}{l}
a=m^{2} \frac{2+N_{l}\left(N_{s}-1\right)\left(3+N_{l}\left(2 N_{s}-1\right)\right)}{6 N_{l}^{2} N_{s}^{2}} \\
b=m^{2} \frac{N_{l}-1}{N_{l}^{2} N_{s}^{2}} \\
c=m^{2} \frac{2+6 N_{l} N_{s}\left(N_{l}-1\right)+N_{l}\left(N_{s}-1\right)\left(3+N_{l}\left(2 N_{s}-1\right)\right)}{6 N_{l}^{2} N_{s}^{2}} \\
d=1 \\
e=-m \frac{N_{l}\left(N_{s}-1\right)+1}{N_{l} N_{s}} \\
f=-m \frac{1+2\left(N_{l}-1\right)+N_{l}\left(N_{s}-1\right)}{N_{l} N_{s}}
\end{array}\right.
$$

and where

$$
\gamma_{1}=N_{s} \gamma_{1}^{\prime}, \quad \gamma_{2}=N_{s} \gamma_{2}^{\prime} \quad \text { and } \quad \gamma_{3}=N_{s} \gamma_{3}^{\prime}
$$

\section{Comparison of performances and experimental validation}

\section{Comparison between three winding arrangements}

Equation (14) gives the electrostatic energy stored in the volume of the transformer as a function of two independent voltages $V_{1}$ and $V_{3}$. The value of $V_{3}$ can be fixed by connecting one of the two primary terminals to a point of the secondary winding; this is equivalent to fix a parameter $k$ in the $[0,1]$ interval, such as $V_{3}=k m V_{1}$. Thus the quadratic form (1) can be simplified by

$$
W=\frac{1}{2} C_{p}\left(m V_{1}\right)^{2}
$$

by replacing $V_{3}$ with $k m V_{1} . C_{p}$ is the equivalent parasitic capacitance presented on Fig.1 and Fig.6, which value, depending on $k$, strongly affects the injected power in the DBD device [9]. In order to compare the winding arrangements, the theoretical value of $C_{p}$ (Fig.6) is plotted on Fig.7 with 4 secondary layers $\left(N_{l}=\right.$ 4), splitted in various number of sections $N_{s}$. It is shown in this figure that the value of $C_{p}$ can be minimized by wisely connecting a primary terminal to the secondary winding ( choosing the best value for $k$ ), and that splitting the secondary winding in several sections tends to reduce the value of $C_{p}$.

\section{Experimental validation of the method for the estimation of the capacitance}

Three transformers with winding arrangements as described in Fig.4a, 4b, 4c that meet the following specifications (Table I) have been realized. Their physical characteristics are presented on Table II. On the one hand, the values of $C_{1}, C_{2}, C_{3}$ have been measured according to the method presented in [11] with a small signal transfer function analyzer and on the other hand they have been calculated by identifying the quadratic form coefficients of (14) and those of (1). The experimental comparisons for 


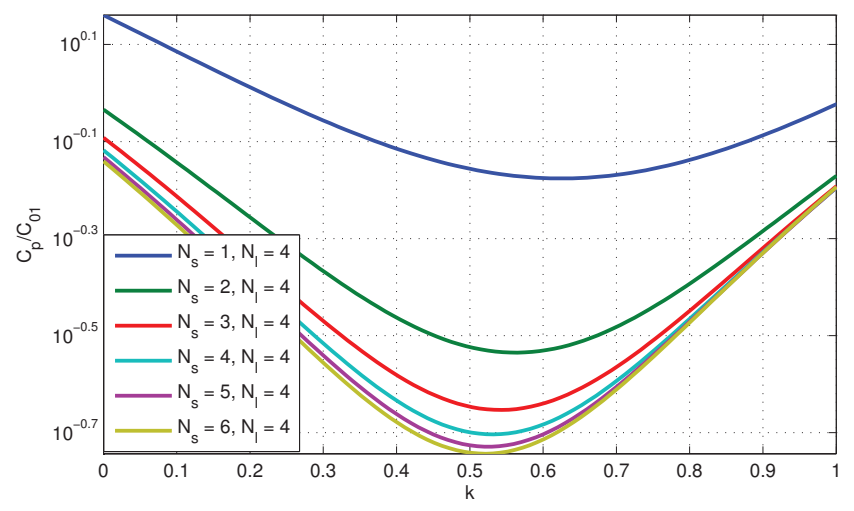

Fig. 7: Value of $C_{p}$ as a function of $k$.

Table I: Specifications of the transformers

\begin{tabular}{ll}
\hline Parameters & Values \\
Application & $\mathrm{HV}-\mathrm{HF}$ supplying excimer lamps \\
Max. Secondary Voltage & $5 \mathrm{kV}$ \\
Primary effective current & $1 \mathrm{~A}$ \\
Frequency range & $80-200 \mathrm{kHz}$ \\
\hline
\end{tabular}

Table II: Characteristics of the transformers

\begin{tabular}{ll}
\hline Parameters & Values \\
Magnetic Core & E80/38/20-3F3 (Ferroxcube) \\
Nb of turns (primary winding) & $26\left(N_{l}=1\right)$ or $52\left(N_{l}=2\right)$ \\
Transformer ratio & $\approx 10$ \\
Insulation layer (zone 1) & Acrylic $4.5 \mathrm{~mm}\left(\varepsilon_{r}=2.5\right)$ \\
Insulation layer (zone 2) & Acrylic $2 \mathrm{~mm}$ \\
Insulation layer (zone 3) & Air $>5 \mathrm{~mm}($ very little effect) \\
\hline
\end{tabular}

each transformer are summarized in Table III. The error in the value of $C_{p}$ (theoretical and measured) can be seen on Fig. 8 for each winding arrangement. Comparing the measured and the theoretical values of $C_{1}, C_{2}$ and $C_{3}$ confirms that the straight analytical approach previously developed gives a good enough approximation of $C_{p}$ for designers' preoccupation. Indeed, it makes the trends emerge despite the error on $C_{p}$ value which is about $20 \%$ in the worst case (the worst value of $k$ within the three arrangements). It is also possible to see that wisely connecting a primary terminal to the secondary winding minimizes the equivalent parasitic capacitance in the secondary, as desired. Moreover, experimental validation confirms that for a given number of turns, splitting the secondary winding in several sections tends to diminish $C_{p}$ value as predicted in Fig.7.

\section{Conclusion}

The proposed method provides an efficient and easy-to-use tool to estimate the value of the parasitic capacitances in the step-up transformer for a DBD system, according to the organization and the size of its windings. It is theoretically and experimentally demonstrated that splitting the secondary winding into several sections connected in series, and wisely connecting a primary terminal to the secondary winding, helps to strongly reduce the parasitic capacitance effects by minimizing the electrostatic energy stored in the transformer volume. 
Table III: Values of $C_{1}, C_{2}$ and $C_{3}$ for the three transformers.

\begin{tabular}{|c||c|c|c||c|c|c||c|c|c|}
\hline \multicolumn{1}{|c||}{} & \multicolumn{3}{c||}{$T_{1}: N_{s}=1 / N_{l}=1$} & \multicolumn{3}{c||}{$T_{2}: N_{s}=1 / N_{l}=2$} & \multicolumn{3}{c|}{$T_{3}: N_{s}=2 / N_{l}=2$} \\
\hline & $C_{1}(\mathrm{nF})$ & $C_{2}(\mathrm{pF})$ & $C_{3}(\mathrm{pF})$ & $C_{1}$ & $C_{2}$ & $C_{3}$ & $C_{1}$ & $C_{2}$ & $C_{3}$ \\
\hline Measured & 1.21 & -136 & 166 & 3.21 & -206 & 243 & 2.2 & -210 & 250 \\
Calculated & 1.02 & -140 & 174 & 2.93 & -192 & 226 & 1.74 & -173 & 207 \\
\hline
\end{tabular}

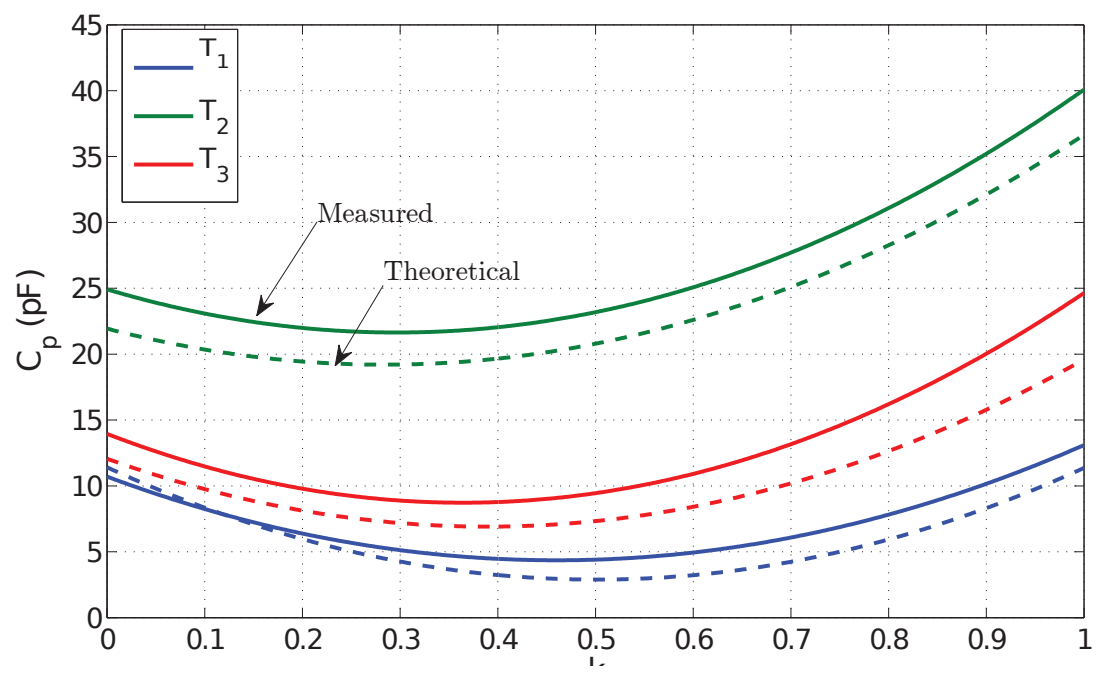

Fig. 8: Value of $C_{p}$ as a function of $k$.

\section{References}

[1] Ulrich Kogelschatz. Dielectric-barrier discharges: Their history, discharge physics, and industrial applications. Plasma Chemistry and Plasma Processing, 23:1-46, 2003. 10.1023/A:1022470901385.

[2] Xueji Xu. Dielectric barrier discharge properties and applications. Thin Solid Films, 390(12):237 - 242, 2001. Proceedings of the 5th Asia-Pacific Conference on Plasma Science ; Technology and the 13th Symposium on Plasma Science for Materials.

[3] M. Facta, Z. Bin Salam, and Z. Bin Buntat. The development of ozone generation with low power consumption. In Innovative Technologies in Intelligent Systems and Industrial Applications, 2009. CITISIA 2009, pages 440-445, 2009.

[4] M. Lomaev, E. Sosnin, V. Tarasenko, D. Shits, V. Skakun, M. Erofeev, and A. Lisenko. Capacitive and barrier discharge excilamps and their applications (review). Instruments and Experimental Techniques, 49:595-616, 2006. 10.1134/S0020441206050010.

[5] H. Piquet, S. Bhosle, R. Díez, A. Toumi, and G. Zissis. Innovative power supply concepts for dbd excilamps. pages 693810-693810-14, 2007.

[6] R. Díez, H. Piquet, M. Cousineau, and S. Bhosle. Current-mode power converter for radiation control in dbd excimer lamps. Industrial Electronics, IEEE Transactions on, 59(4):1912 -1919, april 2012.

[7] R. Díez, JP. Salanne, H. Piquet, S. Bhosle, and G. Zissis. Predictive model of a dbd lamp for power supply design and method for the automatic identification of its parameters. The European Physical Journal Applied Physics, 37:307-313, 2007.

[8] N. Naudé, J-P. Cambronne, N. Gherardi, and F. Massines. Electrical model of an atmospheric pressure townsend-like discharge (aptd). The European Physical Journal Applied Physics, 29:173-180, 2005.

[9] X. Bonnin, H. Piquet, N. Naudé, N. Gherardi, and J-M. Blaquière. Alimentation électrique des dispositifs de décharge barrière diélectrique pour le traitement de surface. In Électrotechnique du futur, Belfort, 2011.

[10] F. Blache, J.-P. Keradec, and B. Cogitore. Stray capacitances of two winding transformers: equivalent circuit, measurements, calculation and lowering. In Industry Applications Society Annual Meeting, 1994., Conference Record of the 1994 IEEE, pages 1211 -1217 vol.2, oct 1994.

[11] A. Schellmanns, J.-P. Keradec, J.-L. Schanen, and K. Berrouche. Representing electrical behaviour of transformers by lumped element circuits: a global physical approach. In Industry Applications Conference, 1999. Thirty-Fourth IAS Annual Meeting. Conference Record of the 1999 IEEE, volume 3, pages 2100 -2107 vol.3, 1999. 